\title{
Kernos
}

Revue internationale et pluridisciplinaire de religion grecque antique

18 | 2005

Varia

\section{Comment effrayer les enfants : le cas de Mormô/ Mormolukê et du mormolukeion}

\section{Maria Patera}

\section{OpenEdition \\ Journals}

Édition électronique

URL : http://journals.openedition.org/kernos/1910

DOI : 10.4000/kernos. 1910

ISSN : 2034-7871

Éditeur

Centre international d'étude de la religion grecque antique

Édition imprimée

Date de publication : 1 janvier 2005

Pagination : 371-390

ISSN : 0776-3824

Référence électronique

Maria Patera, "Comment effrayer les enfants : le cas de Mormô/Mormolukê et du mormolukeion », Kernos [En ligne], 18 | 2005, mis en ligne le 14 septembre 2011, consulté le 20 avril 2019. URL : http:// journals.openedition.org/kernos/1910; DOI : 10.4000/kernos.1910 


\section{Comment effrayer les enfants : le cas de Mormô/Mormolukê et du mormolukeion}

\footnotetext{
Résumé : Cet article examine certains récits concernant un personnage faisant partie de l'univers des chambres enfantines, un croque-mitaine utilisé par les adultes pour effrayer les enfants. Mormô est une figure féminine fortement associée aux enfants et représentant l'aspect «vain» de l'épouvante qu'ils éprouvent. Être verbal, son nom est l'attribut essentiel de l'épouvante qu'elle provoque, nom que les sources associent à celui de Gorgô. Association qui se retrouve dans l'usage du terme mormolukeion, parallèle du gorgoneion, et signifiant à la fois «épouvantail » et "masque », faisant ainsi le lien entre les récits «enfantins » et la scène de théâtre.
}

Abstract: How to scare children: the case of Mormo/Mormolyke and of the mormolykeion. This article examines narratives about a figure belonging to the world of childhood, a bogey used by adults to frighten children. Mormo is a feminine figure deeply associated with children and represents the "vain" side of their terror. She is a verbal being and her name is the main characteristic of the terror that she causes, a name that the sources associate with that of Gorgo. We find the same association in the use of the term mormolykeion (compared to gorgoneion), which signifies both "bogey" and "mask", and so links the "childish" narratives with the theatrical stage.

Parmi les récits des chambres enfantines, ceux que les nourrices ou les mères racontaient aux enfants, parmi ces récits de conteurs anonymes certains étaient destinés à effrayer les enfants turbulents dans le but de les assagir . Plusieurs personnages étaient ainsi mis en scène, en général des figures féminines, parmi lesquelles Mormô/Mormolukê fut la plus étroitement associée aux craintes enfantines ${ }^{2}$.

Mormô/Mormolukê est qualifiée de $\varphi o ́ \beta \eta \tau \varrho o \nu^{3}$, terme à traduire par le français «épouvantail» qui, au sens figuré, désigne «ce qui inspire de vaines ou d'excessives terreurs, ce qui fait horreur ou inquiète fortement, parfois sans

\footnotetext{
1 Un épisode de la vie d'Ésope constitue une bonne illustration de l'usage des épouvantails : ce dernier qui était, semble-t-il, d'une laideur proverbiale, propose à un marchand d'esclaves de

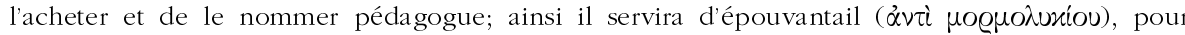

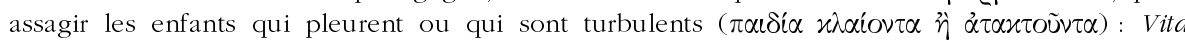
Aesopi Westermanniana XV, 4-16, 4 (éd. H. Hunger, Corpus Fabularum Aesopicarum, I, 1, Leipzig, 1970, p. 83). Les mères inventent des épouvantails dans le même but : $c f$. Jean Chrysostome, Ad Stagirium a daemone, PG 47 (1858), col. 434, 1-5; Basile de Césarée, Homilia dicta tempore famis et siccitatis, PG 31 (1857), col. 328, 27-31.

Cf. M. PATERA, Phobêtra et mormolukeia. Figures de l'épouvante et de la peur dans l'imaginaire grec, thèse de doctorat EPHE, 2004.

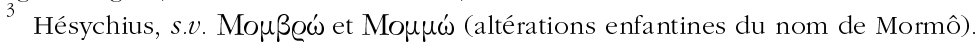


raison; ou, ce qui est mis en avant, ce qui est utilisé pour effrayer » ${ }^{4}$, aspects qui se retrouvent tous dans le caractère du personnage qui nous occupe et dans les termes apparentés.

\section{Le personnage de Mormô}

Malgré leur nombre important, les sources mentionnant Mormô restent très généralement allusives. L'histoire, l'aspect et les contours de ce personnage restent flous. Lorsqu'elle n'est pas identifiée à d'autres figures similaires ${ }^{5}$, elle est décrite comme une femme corinthienne ${ }^{6}$ qui aurait dévoré ses propres enfants et qui fait partie des apparitions $(\varphi \alpha \sigma \mu \alpha \tau \alpha)$ « qui effrayent et frappent les enfants de crainte (ou de stupeur) ». Elle aurait eu une patte d'âne ${ }^{8}$ et aurait aussi été dotée du pouvoir de métamorphose $e^{9}$. Son apparence est peu documentée : selon Erinna c'est un quadrupède à grandes oreilles qui erre en apportant l'épouvante ${ }^{10}$. Selon une scholie à Théocrite ${ }^{11}$, il s'agirait d'un cheval. D'autre part, le composé lukos du nom de Mormolukê, renverrait au loup $^{12}$. Enfin, chez Philostrate, une créature qualifiée entre autres ${ }^{13}$ de mormolukia, ayant pris l'apparence d'une belle femme, projette de dévorer un jeune homme, heureusement sauvé par Apollonios de Tyane.

En réalité, le plus intéressant dans ce personnage peu déterminé, c'est son

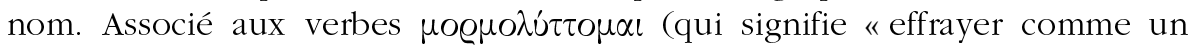
croque-mitaine » mais aussi «craindre ») et $\mu о Q \mu u ́ \sigma \sigma o \mu \alpha \iota$ ( faire peur comme un épouvantail »), Mormô est un «mot populaire expressif » qui peut être employé comme une exclamation destinée à effrayer les enfants, et qui

\footnotetext{
4 Trésor de la langue française: dictionnaire de la langue du XIX et du XX゚ siècle, 1789-1960, CNRS, Institut national de la langue française, Paris, 1971, s.v. «épouvantail».

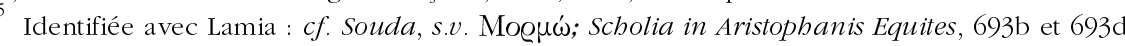
(éds D.M. JONES, N.G. Wilson, Scholia in Aristophanem I, 2 [1969], p. 167). Avec Lamia et Gellô : Scholia in Theocriti Idyllia, XV, 40 (éd. WendeL). Avec Lamia et Empousa : Philostrate, Vie d'Apollonios de Tyane IV, 25.

Scholia in Aristidem, Panathênaïkos, 102 (éd. DINDORF III [1829], p. 42).

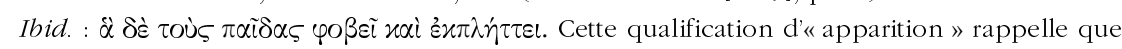
les termes «fantôme » et « spectre » sont quasi synonymes d'«épouvantail » selon le TLF.

Ce qui est un trait majeur d'un autre épouvantail du nom d'Empousa : J.O. Tzetzès, Commentarium in Ranas, 293 (éd. W.J.W. KOSTER, Scholia in Aristophanem IV, 3 [1962], p. 780); Etymologicon Magnum, s.v. 'E $\mathrm{E} \pi \mathrm{ov \sigma \alpha}$; Eustathe, Commentarii ad Homeri Odysseam XI, 634 (éd. VAN DER VALK, I [1971], p. 442, 32-35); Souda, s.v. "E $\mu \pi 0 v \sigma \alpha$.

9 Ce qui est le cas de tous les épouvantails auxquels elle est assimilée, notamment Empousa, la plus protéiforme de ces créatures: cf. Aristophane, Grenouilles 288-304; Etymologicon

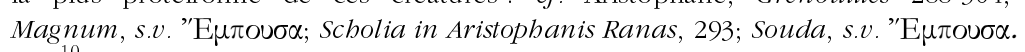

${ }^{10}$ Erinna F Ib, 25-27 (éd. DieHL I, 4).

11 Scholia in Theocriti Idyllia, XV, 40

12 Le loup est lui-même un épouvantail pour les enfants et C. MAINOLDI, L'image du loup et du chien dans la Grèce ancienne d'Homère à Platon, Paris, 1984, p. 206 et n. 49, l'associe à Mormolukê.

${ }^{13}$ Il s'agit plus précisément d'une des Empousai, Lamiai ou Mormolukiai : Philostrate, Vie d'Apollonios de Tyane IV, 25.

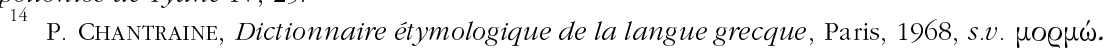


repose peut-être sur une onomatopée. Son nom traduit des bruits confus et des grondements, des sonorités susceptibles de provoquer l'effroi, mais aussi de traduire la crainte ressentie ${ }^{15}$. Des termes fondés sur la même racine expri-

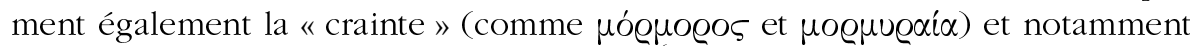

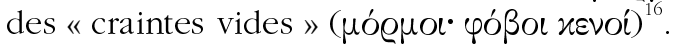

L'usage du nom de Mormô pour provoquer l'effroi est illustrée par un mot de Théocrite ${ }^{17}$ : «Mormô, le cheval mord »; c'est en effrayant ainsi son enfant en pleurs qu'une mère le dissuade de venir se promener avec elle. Il s'agit ici d'un usage interjectif du terme. Seulement, le scholiaste le prend au mot et explique que la mère dit à l'enfant ${ }^{18}$ : «je ne t'emmènerai pas avec moi, enfant, car la Mormô-cheval ${ }^{19}$ mord ». De toute manière, même s'il s'agit d'une exclamation, elle est fortement associée par le poète à un cheval dangereux ${ }^{20}$. Et une Mormô qui change d'aspect pourrait très bien prendre l'aspect d'un cheval, ou d'une autre bête.

L'usage du terme pour exprimer la crainte ressentie est bien illustré par Aristophane. Dans les Cavaliers, le Charcutier, voyant venir son ennemi juré, le Paphlagonien, manifestement en colère, s'écrie que ce dernier s'avance «comme s'il voulait m'engloutir. Mormô de l'effronterie ! » ${ }^{21}$ qu'on pourrait traduire par «Brrr! quelle effronterie ! » ${ }^{22}$ Aristophane associe ainsi au verbe « engloutir » $\left(\varkappa \alpha \tau \alpha \pi^{i} i v \omega\right)$ Mormô, la créature qui dévorait les enfants. Il renforce de cette manière la portée significative du vers, tout en associant le Paphlagonien à un épouvantail dont la sonorité même du nom évoque la crainte, mais une crainte réservée aux enfants et par conséquent inadéquate chez un adulte.

15 F. SKODA, Le redoublement expressif: un universal linguistique, Paris, 1982 (Société d'études linguistiques et anthropologiques de France, 15), \3.84, p. 96.

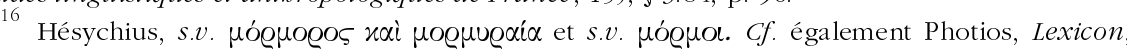

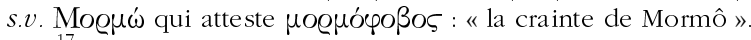

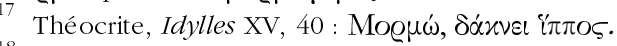

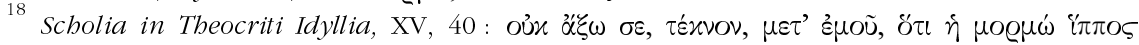
Sóxvઘl.

Sarah Isles Johnston suppose que dans une aire spatiale donnée (peut-être la Sicile, patrie de Théocrite?) Mormô était imaginée comme en partie équine; l'auteur suppose un terme mormippos qui correspondrait au terme mormolukê: "mormô-loup » utilisé, avant l'époque romaine, uniquement par des auteurs athéniens; ce qui lui fait suggérer qu'en Attique, Mormô était typiquement représentée comme en partie louve : $c f$. S.I. JOHNSTON, «Defining the Dreadful: Remarks on the Greek Child-killing Demon », in M. MEYER, P. MIRECKI (éds), Ancient Magic and Ritual Power, Leyde et al., 1995, p. 361-387, p. 375-378; ead., Restless Dead. Encounters Between the Living and the Dead in Ancient Greece, Berkeley et al., 1999, p. 182

${ }^{20}$ Cette mère effraye son enfant avec ses propres peurs : en effet, un peu plus loin (Théocrite, Idylles, XV, 58), elle explique qu'elle craint fortement les chevaux depuis son enfance.

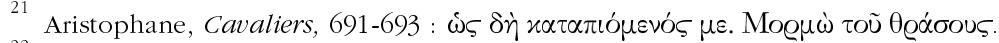

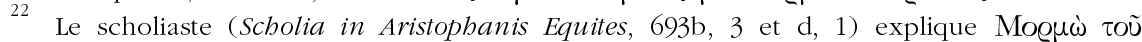

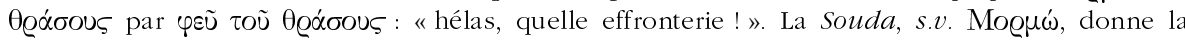
même explication. 


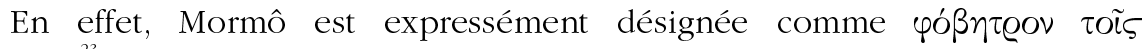
$\pi \alpha \iota \delta i o ı \varsigma^{23}$. Dans les sources, Mormô paraît très efficace dans son rôle d'épouvantail d'enfants, et l'effroi qu'elle inspire tout aussi efficace pour obtenir leur obéissance. Nous en avons eu un exemple avec «le cheval qui mord» de Théocrite. Cependant, la crainte qu'inspire Mormô est doublée du ridicule qu'évoque une peur vaine face à une chose qui n'existe pas.

Aristophane a beaucoup utilisé cet aspect ridicule de la crainte qu'inspire Mormô. Dicéopolis, dans les Acharniens, s'écrie devant le bouclier du stratège Lamachos, orné d'une Gorgô (destinée évidemment à effrayer les ennemis) : "éloigne de moi la Mormô ». Ce que la scholie explique par : "au lieu des

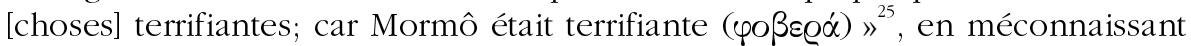
quelque peu le caractère grotesque que confère cette appellation aussi bien à la Gorgô peinte sur le bouclier qu'à Lamachos lui-même. Trygée, dans la Paix, dit à un choreute qui fait preuve de mauvaise volonté pour délivrer la Paix prisonnière, en le nommant Lamachos : «Nous ne craignons pas, homme, ta Mormô ${ }^{26}$; il s'agit toujours du même bouclier ${ }^{27}$.

Peur ridicule chez les adultes, peur sans objet, de sorte que l'expression «Untel a peur de ceci comme les enfants ont peur de Mormô (ou des Mormones, au pluriel)» a eu un certain succès. Xénophon ${ }^{28}$ l'emploie à $^{\prime}$ propos des alliés des Lacédémoniens que ces derniers accusent de craindre

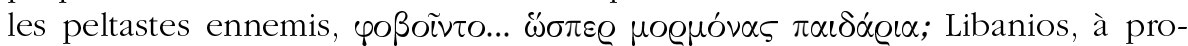
pos de celui qui craint les Perses ${ }^{29}$ et aussi, à propos d'un couard qui « fuit plus les jugements que les enfants [ne fuient] les Mormones » ${ }^{30}$. Dion Chrysostome $^{31}$ considère que chacun peut avoir sa source particulière de crainte, comme chaque enfant craint une Mormô et est habitué à craindre celle-là; mais ce comportement est honteux lorsqu'il s'agit de personnes importantes.

\section{Le mormolukeion, épouvantail et masque}

Le même genre d'expression est très couramment composé avec le terme de mormolukeion au lieu de celui de Mormô. Ce terme, dérivé de Mormô ${ }^{32}$, de loin le plus fréquemment attesté, désigne aussi bien l'«épouvantail» en général que le «masque » de théâtre. Il est souvent difficile de distinguer les

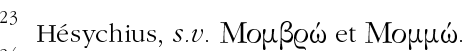

24 Aristophane, Acharniens, 582.

Scholia in Aristophanis Acharnenses, 582 (éd. N.G. WILson, Scholia in Aristophanem I, 1b

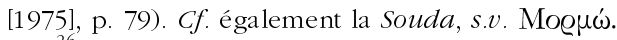

Aristophane, Paix, 474

27 Scholia in Aristophanis Pacem, 474 (éd. DÜBNER)

${ }^{28}$ Xénophon, Helléniques IV, 17.

29 Libanios, Pro templis XXX, 38, 12.

Libanios, Contra Tisamenum XXXIII, 42, 7.

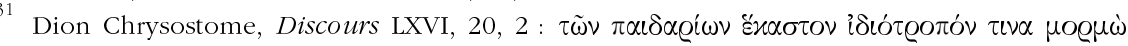

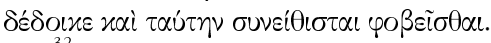

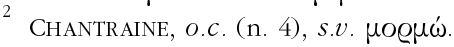


deux significations : les masques de théâtre peuvent très bien être des sujets d'effroi pour les enfants, et leurs épouvantails être des masques.

Parfois, la signification d'«épouvantail » est claire. Aristophane, par exemple, utilise le terme mormolukeion, "ce qui effraye», pour qualifier les molosses, chiens que les maris nourrissent pour servir d'«épouvantails aux adultères ${ }^{33}$. Platon ${ }^{34}$ compare la peur des adultes face à la mort aux peurs enfantines face aux mormolukeia : il y a en chacun de nous un enfant effrayé, assure-t-il, et chaque enfant a craint un jour un mormolukeion. Proclus ${ }^{35}$ met les croyances aux êtres terrifiants qui punissent les condamnés dans les enfers

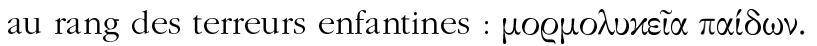

Chez Héliodore ${ }^{36}$, des adultes disent d'eux-mêmes l'énorme terreur qu'ils ressentent à la seule évocation du nom de Thisbé (la servante scélérate), nom qu'ils qualifient de mormolukeion, ce qui rappelle que le seul son produit par le nom de Mormô effrayait les enfants. Ce passage souligne l'absurdité de la crainte ressentie (puisqu'on nous dit que la servante est morte). Un peu plus loin $^{37}$, leur interlocuteur leur demande si vraiment Thisbé leur fait peur ou s'ils veulent juste se moquer de lui, s'ils lui jouent un jeu, en

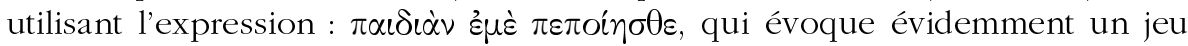
d'enfant.

Ce genre d'expression fit également une belle carrière chez les auteurs chrétiens dans toutes sortes de contextes ${ }^{38}$. Clément d'Alexandrie ${ }^{39}$ veut que les chrétiens cultivés profitent de l'héritage de la philosophie païenne, sans craindre qu'elle ne les «enlève » ( $\mu \dot{\eta} \dot{\alpha} \pi \alpha \gamma \alpha \dot{\gamma}$ n $\alpha \dot{u} \tau o u ̀ \varsigma)$, comme les enfants craignent les épouvantails. Ce qui est bien dans les habitudes des mormolukeia: ils enlèvent, saisissent, attrapent les enfants ${ }^{40}$. Plusieurs Pères de l'Eglise ${ }^{41}$ distinguent leurs paroles des faux mormolukeia inventés dans les récits mensongers des nourrices ('̊ $\left.\pi^{i} \pi \lambda \alpha \sigma \tau \alpha \delta i \eta \gamma \eta \dot{\eta} \mu \alpha \tau \alpha\right)$ pour faire taire les jeunes indisciplinés. Jean Chrysostome ${ }^{42}$, plus radical, compare l'effet des

33 Aristophane, Thesmophories, 413-417.

34 Platon, Phédon, 77e.

35 Proclus, In Platonis Rem Publicam Commentarii, 180, 19

${ }^{36}$ Héliodore, Les Éthiopiques VI, 2, 1.

37 Héliodore, Les Éthiopiques, VI, 2, 2.

38 Cf. par exemple : Basile de Césarée, Lettres XXV, 1, 16-17; Clément d'Alexandrie, Le pédagogue I, vI, 33, 3; Didyme l'Aveugle, Commentaire aux Psaumes XXXIII, 10, 196, 8; Eusèbe de Césarée, De la vie de l'empereur Constantin III, 54, 4, 2; VIII, 1, 1-3; V, 6, 4-7; Jean Chrysostome, Homiliae XC in Matthaeum, XXVIII, PG 57 (1860), col. 353, 38-40; id., Discours sur Babylas, 81, 12-14; Théodoret de Cyr, Quaestiones in Genesim, PG 80 (1860), col. 97, 10-22; id., Histoire ecclésiastique $\mathrm{V}, 11,13,4$, 6-7.

39 Clément d'Alexandrie, Stromates, VI, 10, 80, 5.

40 Comme on le disait expressément de l'un d'eux, Lamia : cf. Scholia in Aristidis Panathênaikos, 102.

Basile de Césarée, Homilia dicta tempore famis et siccitatis, PG 31 (1857), col. 328, 27-31; id., De futuro justitio, PG 32 (1857), col. 1304, 4-9; Jean Damascène, Sacra Parallela, PG 95 (1864), col. 1184, 37-41.

Jean Chrysostome, Ad Stagirium a daemone, PG 47 (1858), col. 434, 1-9. 
mormolukeia que les mères utilisent pour faire revenir les enfants à elles à l'effet des ruses du Malin (ó Пovn@ós) : lorsqu'il nous effraye, nous nous tournons précipitamment vers Dieu.

Ces affirmations sont suffisantes pour établir que les mormolukeia furent tout à fait efficaces pour assagir les enfants turbulents. Cependant leur emploi - et ce dans la grande majorité des sources que nous avons citées - est ironique. Les adultes lâches craignent des épouvantails aussi vains et inexistants que ceux qui terrorisent leurs enfants.

Les masques ont également un aspect épouvantable, ce sont des moyens tout aussi efficaces pour effrayer les marmots récalcitrants, effroi qui se retrouve dans l'usage du terme mormolukeion. Hésychius ${ }^{43}$ explique que les mormolukeia sont «les masques des tragédiens ». Une scholie à Platon ajoute une remarque intéressante: "on appelle mormolukeia les masques des acteurs, masques que les Doriens appellent gorgia ${ }^{44}$. Avec ces masques, les

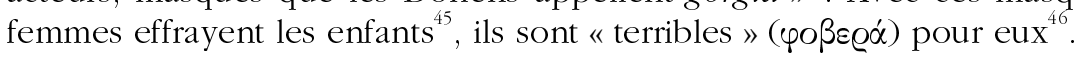

Aristophane parle également de "masque comique» ( $\omega \omega \mu \omega \delta$ iòv $\mu \circ Q \mu O-$ $\lambda u \varkappa \varepsilon i o v)^{47}$, terme qui désignerait un masque laid et grotesque ${ }^{48}$. Une scholie à Aristophane $^{49}$ affirme que ce terme désigne des masques aussi bien tragiques

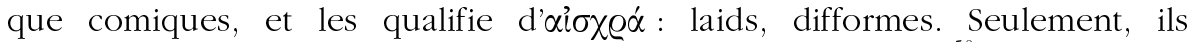
n'étaient pas uniquement utilisés au théâtre: Aristophane ${ }^{50}$ les suspend également aux temples de Dionysos; c'est même à cela qu'on reconnaît son temple, ils servent par leur présence à marquer l'espace du dieu. Selon Henri Jeanmaire ${ }^{51}$, ces mormolukeia étaient exposés «à titre apotropaïque ou pour conjurer les influences malignes »; ils attestent un lien avec l'univers dionysiaque; l'auteur paraphrase le fragment d'Aristophane, en disant que le dionysisme se rencontre partout où l'on suspend ce genre de masque grimaçant et

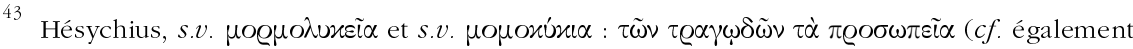

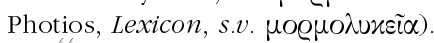

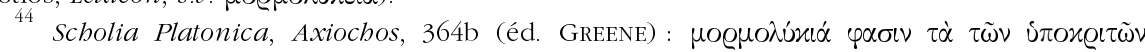

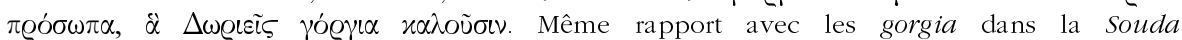

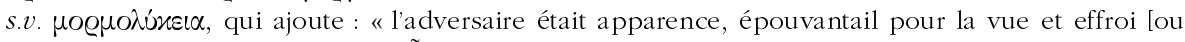

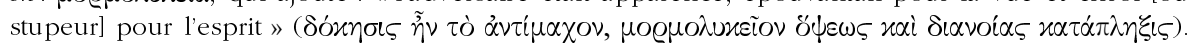

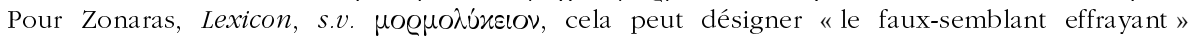

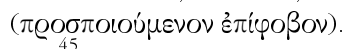

45 Scholia Platonica, Gorgias, 473d.

46 Timée, Lexicon vocum platonicarum, s.v. $\mu о Q \mu о \lambda u ́ x \varepsilon\llcorner\alpha$.

47 Aristophane, F 31 (éds Austin et KASSEL).

48 J. TAlllardat, Les images d'Aristophane, Paris, $1965^{2}$ (1962), 』884, p. 491, ajoute que le sens figuré de mormolukeion en tant que masque n'est pas autrement connu, ce qui est évidemment invalidé par toutes les occurrences mentionnées.

49 Scholia in Aristophanis Pacem, 474.

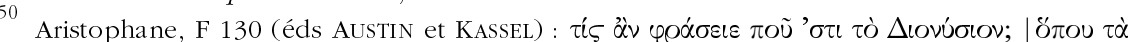

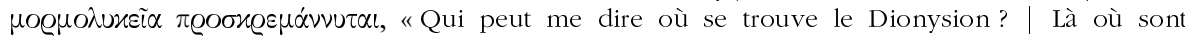
suspendus les masques ».

H. Jeanmaire, Dionysos. Histoire du culte de Bacchus, Paris, 1951, p. 310
} 
effrayant. C'est possible. Cependant, Françoise Frontisi-Ducroux ${ }^{52}$ propose d'identifier ces mormolukeia aux masques de satyres à rôle apotropaïque suspendus aux temples de Dionysos.

Ces masques «façonnés pour l'effroi (ou pour la stupeur) ${ }^{53}$ qui ont le même effet que Mormô sur les enfants ${ }^{54}$, participent pourtant de l'épouvante générale que provoquent les masques sur ces derniers. Jean Chrysostome parle en effet des "masques et autres épouvantails » ${ }^{55}$, associant ainsi toutes espèces de masque, et non seulement les «laids et grotesques », à la créature épouvantable qui nous occupe. Clément d'Alexandrie parle de la vérité qui se tient dissimulée, comme se cache «le véritable visage sous les masques $»^{56}$. Comme Mormô, le mormolukeion est utilisé pour épouvanter, on se cache derrière lui, il est faux. En désignant ainsi le masque de théâtre, cette fausseté est mise en valeur : le masque-qui-prétend-être-ce-qui-n'existe-pas et l'épouvantail irréel des enfants deviennent synonymes. L'objet faux et l'histoire fausse acquièrent ainsi la même valeur. L'auteur de théâtre se rapproche de la nourrice qui raconte des histoires à dormir debout à des enfants naïs. L'objet qu'il utilise pour représenter autre chose que le réel est nommé mormolukeion, par synonymie avec les inventions effrayantes des nourrices. Le procédé est analogue. En fin de compte, Aristophane utilise ces mormolukeia dont il se moque : il en a besoin. Ce rapprochement entre la scène théâtrale et la chambre enfantine s'effectuant dans l'invention de ce qu'on raconte sur l'une et dans l'autre, est peut-être à l'origine du fait qu'on peut généralement traduire notre terme aussi bien par «épouvantail » que par « masque ».

\section{Mormoluka et les nourrices}

Pour en revenir aux nourrices qui effrayent les enfants pour les rendre sages, il est intéressant de rappeler qu'un passage de Stobée explique que Gorgura fut façonnée en tant que femme d'Achéron" «car les choses de

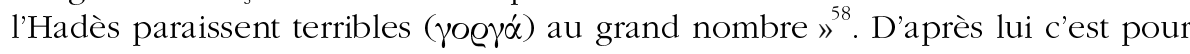

52 F. Frontisi-Ducroux, Du masque au visage. Aspects de l'identité en Grèce ancienne, Paris, 1995 , p. 14. Sur une oenochoé à figures rouges provenant d'Éleusis, nous pouvons voir un exemple de l'utilisation des masques comme épouvantails; dans une scène familière de la vie quotidienne, un enfant poursuit un autre en brandissant un masque de satyre ( $c f$. G.E. MYLONAS, La nécropole ouest d'Éleusis (en grec), Athènes, 1975, t. II, p. 80-82, t. III, pl. 362c).

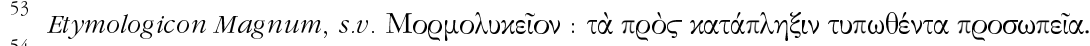

${ }_{54}$ Scholia in Theocriti Idyllia XV, 40 b.

55 Jean Chrysostome, Cathechesis I ad Illuminandos, PG 49 (1859), col. 226 : $\tau \dot{\alpha} \pi \varrho 0 \sigma \omega \pi \varepsilon i \alpha$

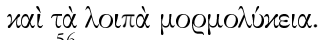

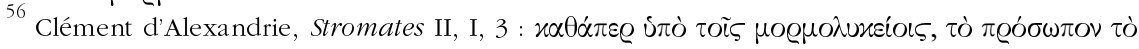
$2 \lambda \eta{ }_{57}\llcorner$ óv.

Sur Gorgura, épouse d'Achéron : $c f$. Apollodore, I, 5, 3. Notons que le terme gorgura (qui signifie, entre autres, un conduit souterrain par lequel s'écoulent les eaux, $c f$. Hésychius, s.v.

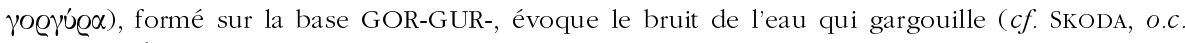
[n. 15], $₫ 3.60$, p. 78). C'est justement l'épouse d'un fleuve qui porte ce nom.

Stobée, Anthologium I, 49, 50, 34. 
cette même raison que Sophron fit de Mormoluka sa nourrice. Mormoluka est donc terrible : il est séduisant de penser que le personnage que les nourrices utilisent pour effrayer les enfants est justement lui-même une nourrice qui a élevé Achéron ${ }^{59}$.

Notons que la nourrice d'Achéron est nommée Mormoluka et non Mormô. Cette créature au rôle subalterne, avec le composé «loup » dans son nom, pourrait peut-être évoquer l'état de servilité des nourrices et des pédagogues dans la société humaine ${ }^{60}$. Selon Sylvie Vilatte ${ }^{61}$, l'état servile des nourrices et des pédagogues pourrait être un moyen de connoter en eux l'animalité. Une animalité qui, dans le cas de Mormoluka, est rendue plus évidente par le composé «loup » de son nom, et qui paraît rejoindre l'animalité ou l'aspect naturel des nourrices divines ${ }^{62}$, qui correspond elle-même à l'animalité de l'enfant $^{63}$. On pourrait donc imaginer que Mormoluka fonctionne de deux manières (en admettant qu'elle était connue comme nourrice d'Achéron et pas seulement par Sophron). Elle évoque d'une part la mort, puisqu'elle est située dans l'Hadès; simultanément, le composé "loup» de son nom évoque un loup terrifiant et certainement anthropophage ${ }^{64}$; évocation renforcée par le son effrayant mormo, qui « désigne les murmures inquiétants et les grondements sourds qui signalent l'arrivée des fantômes »" D'autre part, le fait que Mormoluka soit nourrice ajoute certainement à l'empire que la nourrice qui la

59 Pour Achéron, cf. Odyssée X, 513; Euripide, Alceste, 443; Hérodote, V, 92, 7; Apollodore, I, V, 3; Pausanias, I, 17, 5; V, 14, 2; X, 28, 1 et 4; Virgile, Énéide VI, 295-297; Ovide, Métamorphoses $\mathrm{V}, 539$.

S. VILATTE, « La nourrice grecque, une question d'histoire sociale et religieuse », AC 60 (1991), p. 5-28, surtout p. 19-25.

Ibid., p. 20.

62 Ibid., p. 10 sq. est nourri par la chèvre Amalthée et l'abeille Panacris (Callimaque, Hymne à Zeus (I), 49-50). Ce sont les Nymphes qui servent de nourrices à Zeus (ibid., 33-36, 46-48) et à Dionysos (Hymne homérique à Dionysos, II, 3-4); pour Apollon, c'est Délos anthropomorphisée (Callimaque, Hymne à Délos, (IV) 9-10, 264-265, 275-276). Pour les nourrices animales, cf. Th. Hatzisteliou-Price, Kourotrophos, Cults and Representations of the Greek Nursing Deities, Leyde, 1978, p. 73-74, 77.

63 Vilatte, l.c. (n. 60), p. 20-22. Cf. également le passage de Platon, infra, n. 85. Sur le rapport entre le monde animal et les jeunes, et sur le domptage de ces derniers, $c f$. S. GEORGOUd, "Les jeunes et le monde animal : éléments du discours grec ancien sur la jeunesse » (en grec), Actes du Colloque International Historicité de l'enfance et de la jeunesse, Athènes, 1986, p. 223-229. Cf. également M. GOLDEN, Children and Childhood in Classical Athens, Baltimore/Londres, 1990 , p. 146, qui souligne que toutes les nourrices et tous les paidagôgoi n'étaient pas forcément des esclaves.

${ }^{64}$ Sur le rapport entre loup et anthropophagie, $c f$. par exemple le cas du Mont Lycée : MAINOLDI, o.c. (n. 12), p. 11-18; L. GERnET, "Dolon le loup », in Anthropologie de la Grèce antique, Paris, 1982, p. 201-223 (article paru à l'origine dans l'Annuaire de l'Institut de Philologie et d'Histoire orientales et slaves, IV, Bruxelles, 1936, p. 189-208); A.B. CoOK, Zeus. A Study in Ancient Religion, Cambridge, 1914-1940, I, p. 63-99; W. BURKERT, Homo Necans, Interpretationem altgriechischen Opferinnen und Mythen, Berlin/New York, 1972 (RGVV, 32), p. 84-93; et surtout Ph. Borgeaud, Recherches sur le dieu Pan, Genève, 1979 (Bibliotheca Helvetica Romana, 17), p. 41-48, 64-65. Platon, République X, 619b, établit un rapport entre loup, anthropophagie et tyrannie.

65 FrONTISI-DUCROUX, O.C. (n. 52), p. 13. 
mentionne dans son récit exerce sur son auditoire enfantin; elle partage avec la créature inquiétante de son récit une parenté de fonction, qui suggère qu'elle serait peut-être susceptible de devenir «terrible » à son tour.

Clément d'Alexandrie ${ }^{66}$ accuse les philosophes de brandir les dieux comme

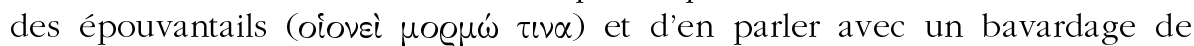

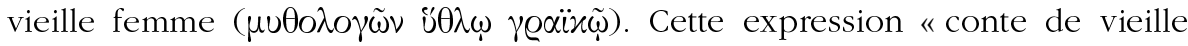
femme » était très utilisée par les auteurs aussi bien païens que chrétiens pour dénigrer des propos qui leur semblaient incohérents; elle était équivalente à "non-sens " ${ }^{67}$ et, à partir de Platon ${ }^{68}$, devint très courante. Chez Platon ${ }^{69}$, le privilège de la transmission des récits est attribué en général aux femmes (nourrices, mères ou vieilles femmes). Ce sont elles qui racontent ces histoires d'épouvantails $^{70}$, elles sont peureuses ${ }^{71}$ et leur crédulité s'oppose à la raison, apanage du sexe masculin. Les récits des vieilles conteuses étaient systématiquement dévalorisés, et l'image de la vieille femme radoteuse a eu un beau succès par la suite ${ }^{72}$. De plus, elles remplissaient souvent le rôle de nourrice ${ }^{73}$ : radoteuses, crédules et portées à la bouteille ${ }^{74}$, elles racontaient naturellement des histoires tellement absurdes que seul un enfant pouvait y croire ${ }^{75}$. D'ailleurs, elles ressemblaient à leur public. Chez les Grecs, les enfants étaient considérés comme "physiquement faibles, moralement incompétents, et mentalement incapables $»^{76}$, à quoi on peut ajouter un manque de courage qui les fait volontiers comparer à des guerriers couards ${ }^{77}$.

66 Clément d'Alexandrie, Le Protreptique VI, 67, 1, 1-3

J. BREMMER, "The Old Women of Ancient Greece », in J. BLOK, P. MASON (éds), Sexual Asymmetry, Studies in Ancient Society, Amsterdam, 1987, p. 191-215, p. 200; R. BuxTON, La Grèce de l'imaginaire: les contextes de la mythologie, trad. M. WECHSLER-BRÜDERLEIN, Paris, 1996 ( $1^{\mathrm{e}}$ éd. Cambridge, 1994), p. 33-36.

68 M. MASSARO, « Aniles Fabellae », SIFC 49, 1-2 (1977), p. 104-135.

69 Platon, Gorgias, 527a; République II, 377c; Lois, X, 887d; Lysias, 205d. Cf. à ce propos P. VEYNE, Les Grecs ont-ils cru à leurs mythes? Essai sur l'imagination constituante, Paris, 1983, p. 150 , n. 56

${ }^{70}$ VEYNE, O.C., p. 54.

${ }^{71}$ Platon, Lois X, 910a: l'auteur y proscrit les sanctuaires privés, car il faut beaucoup d'intelligence pour les fonder correctement, or les femmes en sont manifestement dépourvues; il leur est habituel de consacrer n'importe quoi, ou alors elles sont enclines suite à la crainte de

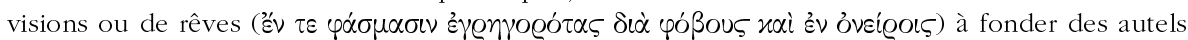
et des sanctuaires.

${ }_{73}$ Cf. MASSARO, l.c. (n. 68), passim

73 BREMMER, l.c. (n. 67), p. 200-201.

${ }^{74}$ Ibid.; H.G. OERI, Der Typ der komischen Alten in der griechischen Komödie, seine Nachwirkungen und seine Herkunft, Bâle, 1948, p. 13-19, 39-46, et pour les servantes ivrognes (dont les nourrices) : p. 53-61.

${ }^{75}$ Pour une vision plus nuancée (et plus positive) du rôle de la vieille femme en Grèce ancienne, $c f$. L. PRATT, "The Old Women of Ancient Greece and the Homeric Hymn to Demeter », TAPhA 130 (2000), p. 41-65.

76 Ibid., p. 5.

77 Eschyle, Euménides 38; Sophocle, F 314, 161 (éd. RADT); Astydamas, II, Hector, F 2 (éd. SNell); Xénophon, Mémorables I, 4, 7; Platon, Gorgias, 479a; Lois XI, 933b; Phédon, 77d-e; République I, 330e; Théétète, 166a, 168d. 
Ces récits, contés par des femmes (et souvent par de vieilles femmes " crédules »), rappellent que Platon ${ }^{78}$ et Aristote $^{79}$ associaient les enfants, les femmes, les esclaves et les animaux. Dans une grande partie des sources, il y $a$ un usage rhétorique du thème de l'enfance pour dénigrer un adversaire ${ }^{80}$. Ils manquent de force physique ${ }^{81}$, ils sont fragiles, et donc incapables de résister efficacement aux attaques et, d'autant plus, aux créatures surnaturelles qui les agressent. Mais surtout, ils manquent de courage, ils sont lâches. Ils sont mentalement faibles, crédules, susceptibles de croire à n'importe quoi (un peu comme ces vieillards qui retournent «en enfance»: $\Delta i \varsigma \pi \alpha i \tilde{\delta} \varepsilon \varsigma$ oi

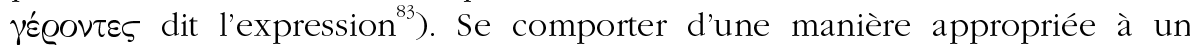
stade antérieur de la vie était en général considéré comme une régression ${ }^{84}$. Les enfants auxquels on attribuait des comportements animaux ${ }^{85}$ étaient attaqués par des créatures qui avaient elles-mêmes acquis par leurs actes des comportements et, partant, des caractéristiques attribués aux animaux. Il est intéressant de relever une analogie de comportement entre l'agresseur et l'agressé : d'un côté, l'enfant est assimilé à l'animal tant qu'il n'a pas été

\footnotetext{
78 Association entre femmes et enfants : Platon, Lettres VIII, 355c. Association entre enfants et animaux : Platon, Lois IV, 710a; XII, 963 e; République IV, 441b-c. Association entre animaux, enfants et esclaves: Platon, Lois VII, 808d-e. Association entre femmes, enfants et animaux : Platon, Théétète, 171e.

${ }^{79}$ Association entre enfants et animaux : Aristote, Éthique à Eudème II, 1224a 29; VII, $1236 \mathrm{a}$ 1; VII, 1238a 33; VII, 1240b 33; Éthique à Nicomaque I, 1100a 1; III, 1111a 28; III, 1111b 8; VI, 1144b 9; VII, 1152b 22; VII, 1153a 32; Histoire des animaux VIII, 588a 31; Les parties des animaux IV, 686b 24; Physique II, 197b 7; Problèmes X, 39, 895a 13; XI, 30, 902b 10; Rhétorique I, 1371a 15; II, 1384b 24. Association entre femmes et enfants : Aristote, De la génération des animaux I, 728 a 17.

${ }^{80}$ GOLDEN, o.c. (n. 63), p. 10

81 Ibid. Eschyle, Agamemnon, 75, 81; Xénophon, Cyropédie IV, 3, 10-11; Aristote, Problèmes XXXIV, 10, 964a 33.

${ }^{82}$ Par exemple, Strabon, I, 2, 8 (= C18-19) explique les légendes merveilleuses de la mythologie grecque par le besoin des hommes politiques d'impressionner le peuple: ainsi "les fondateurs d'États ont accepté ces choses (foudre, égide, trident, etc.) en tant qu'épouvantails

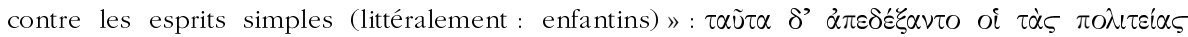

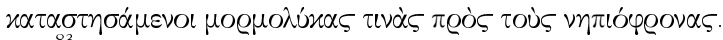

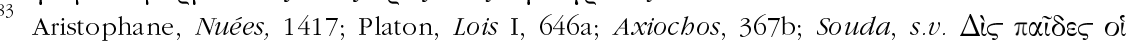

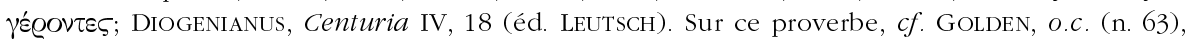
p. 6, et la bibliographie qu'il fournit (p. 184, n. 25).

84 Golden, o.c. (n. 63), p. 10. Cf. Aristoxène, F 35 (éd. WeHrli) : « les enfants ne devraient pas se comporter comme des petits enfants, les jeunes comme des enfants, les adultes comme

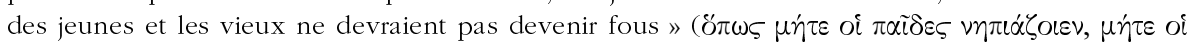

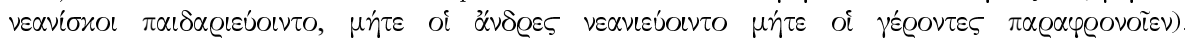
L'association entre vieillards et enfants n'est pas toujours à connotation négative : voir par exemple l'intéressante analyse du rôle des vieillards dans Les Lois de Platon par M. DETIENNE, L'invention de la mythologie, Paris, 1981, p. 185-189.

85 Platon, Lois VII, 808d-e (trad. A. Diès) : « Mais, de tous les animaux, c'est l'enfant qui est le plus difficile à manier; par l'excellence même de cette source de raison qui est en lui, non encore disciplinée, c'est une bête rusée, astucieuse, la plus insolente de toutes » ('O $\delta \dot{\varepsilon} \pi \alpha i \zeta ~ \pi \alpha \dot{\alpha} \nu \omega \nu$

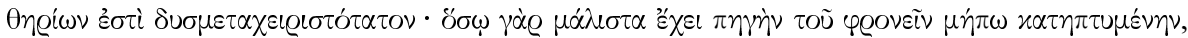
ह̇ंißoù
} 
"dressé »" ${ }^{86}$ de l'autre, son agresseur est considéré comme bestial. On dirait qu'il y a une parenté entre enfant et croque-mitaine : ils n'appartiennent ni l'un ni l'autre pleinement à la société civile. L'un est susceptible d'en faire partie après son "dressage », l'autre en est sorti par ses actes, et il lui est impossible d'y revenir. Les enfants sont également associés aux ivrognes et aux insensés ${ }^{87}$, et leurs nourrices sont portées à la boisson ${ }^{88}$.

\section{Mormô et Gorgô}

Un autre usage intéressant du nom de Mormô est attesté chez Hippolyte ${ }^{89}$. Dans son traité intitulé Réfutation de toutes les hérésies, l'auteur décrit (pour le stigmatiser) un rituel de lécanomancie. Pour connaitre l'avenir, on invoque Hécate sous sa forme la plus terrible, et on l'y nomme entre autres Mormô. Mormô devient donc, au même titre que Gorgô (dans la même phrase) et Baubô, une épithète de la déesse, et s'associe ainsi à elle.

Ce passage a servi à identifier la déesse aux "esprits infernaux» dont feraient partie Mormô et Gorgô. Par exemple, Erwin Rohde ${ }^{90}$ considérait que les noms individuels désignant des spectres de diverses localités (dont Mormô) auraient fini par exprimer tous la même idée générale et se seraient confondus à la fois entre eux et avec "la figure la plus répandue en ce genre : celle d'Hécate». D'ailleurs tous ces personnages féminins auraient «perdu en même temps qu'Hécate une grande partie de leur puissance » et elles n'auraient plus été que des héroïnes de contes d'enfants. Elles auraient toutes appartenu, en même temps qu'Hécate, «au monde souterrain et au royaume des morts ${ }^{91}$. Soulignons pour le moment l'opinion de Jan Bremmer $^{92}$, qui pense qu'il était typique de la recherche de l'époque de Rohde de

86 Cf. GEORGOUDi, l.c. (n. 63), p. 223-224.

87 Aristote, De audibilibus, 801b 5; Éthique à Eudème I, 1214b 30; VII, 1238a 33; Éthique à Nicomaque VII, 1154b 10; Politique VII, 1323a 33; Problèmes XXX, 14, 957a 2.

Cf. GOLDEN, o.c. (n. 63), p. 149 (parmi les épouvantails d'enfants, Lamia est expressément désignée comme une ivrogne: $c f$. Diodore de Sicile, XX, 41, 3-6)

89 Hippolyte, Refutatio omnium haeresium IV, 35, 5 (éd. M. MARCOVICH).

90 E. ROHDE, Seelenkult und Unsterblichkeitsglaube der Griechen, Fribourg, 18982 (1893-1894), II, p. 407-411 (= Psyché, Le culte de l'âme chez les Grecs et leur croyance à l'immortalité, trad. A. Reymond, Paris, 1928, p. 607-610). Hécate serait la mère du dieu du monde souterrain, la

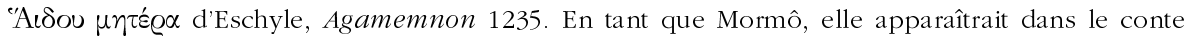
sous la forme de Mormoluka comme nourrice d'Achéron.

91 Cf. également E. Vermeule, Aspects of Death in Early Greek. Art and Poetry, Berkeley et al., 1981 (Sather Classical Lectures, 46), p. 53, qui considère aussi toutes ces créatures comme des figures « infernales »; tout comme J. FonTEnrose, Python. A Study of Delphic Myth and its Origins, Berkeley/Los Angeles, 1959, p. 116, qui les considère comme «des spectres d'Hécate » et des formes de la déesse elle-même; c'est également l'opinion de B.C. DiETRICH, Death, Fate and the Gods. The Development of a Religious Idea in Greek Popular Belief and in Homer, Londres, 1965, p. 342 .

Dans une lettre citée par A. HENRICHS, « Namenlosigkeit und Euphemismus: Zur Ambivalenz der chthonischen Mächte im attischen Drama », in H. HOFManN, A. HARdER (éds), Fragmenta Dramatica, Beiträge zur Interpretation der griechischen Tragikerfragmente und ibrer Wirkungsgeschichte, Göttingen, 1991, p. 161-201, p. 182, n. 44. 
considérer les épouvantails comme ayant perdu leur puissance. Il considère ces personnages simplement comme des "fictions » destinées à effrayer les enfants, et les désigne ainsi parce qu'ils n'appartiennent pas au monde de la croyance adulte.

Pour revenir au rapport entre Hécate, Gorgô et Mormô, mentionnons une épiphanie d'Hécate décrite dans le Philopseudès de Lucien ${ }^{94}$. La déesse y apparaît grande de presque un demi-stade, avec des pieds et une chevelure en forme de serpents, le haut du corps semblable à celui de Gorgô ( $\tau \dot{\alpha} \delta \varepsilon \dot{\varepsilon} \alpha^{\prime} v \omega$

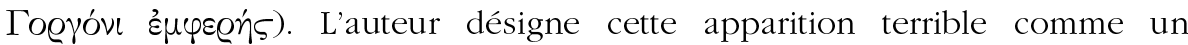
mormolukeion. Notons toutefois que cette description est traitée avec l'ironie associée aux croyances enfantines : les vieillards qui l'écoutent attentivement sont semblables à des enfants en raison de leur crédulité.

K. Dilthey ${ }^{95}$ citait justement ce texte pour prouver que Mormô est une des appellations d'Hécate, qu'il mettait également en rapport avec Baubô, épithète attestée par un papyrus magique ${ }^{96}$. Seulement ici, Hécate est, à notre avis, plus nettement comparée à Gorgô qu'à Mormô. Le terme mormolukeion ne fait que dénoncer le grotesque d'un récit aussi mensonger que celui que Lucien met en scène ${ }^{97}$. Baubô désignant Hécate ferait partie de ces êtres bruyants qui, comme Mormô, imitent un bruit sourd ${ }^{98}$. Origine bruyante du nom de Mormô, considéré comme un impressif sonore " ${ }^{99}$ destiné à effrayer

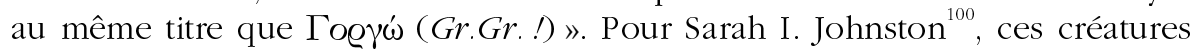
(Lamia, Mormô et Gellô) devaient se trouver parmi celles qu'Hécate avait pour rôle de détourner (en se tenant près de la porte de la maison), pour protéger la santé des enfants et des femmes. Est-ce pour cela qu'elle aurait été parfois assimilée ${ }^{101}$ à elles, la protectrice finissant par se rapprocher étroite-

93 J. Bremmer, The Early Greek Concept of the Soul, Princeton, 1983, p. 101-102.

94 Lucien, Philopseudès, 22-24.

95 K. DiLTHEY, «Ueber die von E. Miller herausgegebenen griechischen Hymnen », RhM 27 (1872), p. 375-419, p. 393, n. 3.

K. Preisendanz, A. Henrichs (éds), Papyri Graecae Magicae: die griechischen Zauberpapyri, vol. II, Stuttgart, 1974, 21, 2. M. OlEndER, "Aspects de Baubô, textes et contextes antiques », RHR 202, 1 (1985), p. 3-53, p. 47. Selon Maurice Olender, "parmi ces démons inquiétants, familiers aux usagers antiques proches d'Hécate et de sa Baubô nocturne », on retrouverait Lamia, Gellô, Mormô et Empousa.

Sur le goût de l'absurde que Lucien attribue à la multitude illettrée, cf. M. CASTER, Lucien et la pensée religieuse de son temps, Paris, 1937, p. 332; Caster parle d'un "véritable cliché dans ce genre d'écrits » (ibid., p. 317), qui est celui « de mettre le lecteur en garde contre les $\mu \nu \theta \omega \dot{\delta} \eta$, et de récuser les poètes ».

98 DilTHEY, l.c. (n. 95), p. 394.

99 SKODA, o.c. (n. 15), \$3.85, p. 96-97. Gorgô est un terme essentiellement auditif fondé « sur une base impressive sonore utilisée originellement pour effrayer (GOR-G-), comme le fait la réduplication $g r \ldots g r \ldots$ qui, dans la langue enfantine, suggère par ses bruits de gorge, l'arrivée d'un monstre prêt à dévorer, donc farouche » : cf. ibid., § 3.61, p. 79.

100 JOHNSTON, o.c. (n. 19), p. 215.

101 Assimilée, du moins avec Empousa, par diverses sources : cf. Aristophane, F 515 (éds

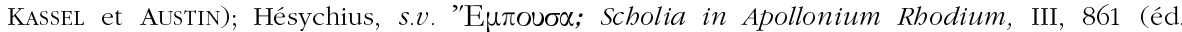
Wendel); J.O. Tzetzès, Commentarium in Ranas, 293. A. Henrichs, l.c. (n. 92), p. 180-187, met en 
ment de la créature contre laquelle elle protège (un peu comme lorsque le même terme alastôr désigne à la fois le criminel et l'esprit vengeur qui le poursuit $\left.{ }^{102}\right)$ ?

À propos de l'épithète «Mormô » qu'Hippolyte attribue à Hécate, on pourrait penser qu'elle fonctionne, en fait, comme nombre d'épiclèses et d'épithètes divines dans le polythéisme grec : le processus de nomination passe du général (Hécate) au particulier, en attribuant à la déesse les caractéristiques de la créature dont elle porte le nom, en lui accordant donc une forme spéciale ${ }^{103}$. Dans cette Hécate-là, ce sont les fonctions de peur évoquées par Gorgô et Mormô qui comptent, un peu comme lorsqu'on attribue à une divinité une épiclèse qui évoque le nom d'une autre divinité. Si Hécate, pourvue du nom de Mormô comme épithète, en acquiert ainsi les qualités et les prérogatives, sa protection contre Mormô pourrait peut-être devenir d'autant plus efficace. Mais il faudrait encore admettre que Mormô était considérée comme une créature réellement dangereuse, qu'on avait besoin d'expulser. Or, selon les sources, un des traits qui semble la caractériser est qu'elle était destinée à effrayer les enfants plutôt que les adultes; les mères ne semblent pas la craindre, ni chercher à en protéger leurs enfants ${ }^{104}$.

Il faut également souligner que parmi ces épouvantails, celui qui entretient la relation la plus étroite avec Hécate est incontestablement Empousa ${ }^{105}$. Mais évidemment, toutes ces créatures sont assimilées également entre elles ${ }^{106}$, et du coup, associées indirectement à Hécate.

Ce qui frappe dans le passage d'Hippolyte, c'est moins la relation d'Hécate avec Mormô que celle que cette dernière entretient avec Gorgô. En ce qui concerne le rapport Hécate/Mormô, c'est le seul texte à notre connaissance qui lie indubitablement la déesse à notre créature; le seul aussi, par conséquent, qui semble accorder au nom de Mormô un peu plus de sérieux que celui qui lui est habituellement attribué (il pourrait s'agir également d'une

doute l'identification d'Hécate et d'Empousa dans le fragment d'Aristophane telle que comprise par la scholie aux Grenouilles d'Aristophane ou par Hésychius.

102 Cf. L. GERNET, Recherches sur le développement de la pensée juridique et morale en Grèce, Paris, 1917, p. 316-317

103 À propos du processus de nomination des dieux grecs, $c f$. P. Brulé, « Le langage des épiclèses dans le polythéisme hellénique (l'exemple de quelques divinités féminines) », Kernos 11 (1998), p. 13-34.

104 En effet, il n'existe pas de témoignages faisant état de moyens prophylactiques utilisés par les mères ou les nourrices expressément contre Mormô. S.I. JOHNSTON, Restless Dead, p. 168-169, pense trouver la mention de tels moyens dans un passage de Platon, Phédon, 77e, parlant d'incantations ou de chants (่̇ $\pi \dot{\alpha} \delta \varepsilon \imath \nu)$ utilisés contre les mormolukeia, mais le ton plaisant du passage, l'utilisation du terme général mormolukeion, ainsi que le fait que l'écrasante majorité des sources atteste que les adultes «fabriquent » ces épouvantails pour effrayer les enfants ( $c f$. par exemple, supra, n. 1 et n. 82), ne permettent pas à notre avis d'attribuer une vraie puissance de Mormô sur l'esprit des adultes. Sur ce passage, $c f$. M. STELla, "Rire de la mort. Le philosophe, la cité, le savoir», in M.-L. Desclos (dir), Le rire des Grecs. Anthropologie du rire en Grèce ancienne, Grenoble, 2000, p. 460-467, p. 464.

105 Cf. supra, n. 101.

106 Cf. supra, n. 5 
manière de discréditer Hécate). Par ailleurs, tout comme Aristophane ${ }^{107}$ donne le «sobriquet» de Mormô à la Gorgô ornant le bouclier de Lamachos, ce texte place les deux épithètes de la déesse côte à côte. Jean-Pierre Vernant ${ }^{108}$ pense que Mormô et les autres créatures terrifiantes traduisent dans le monde des enfants ce que Gorgô représente dans celui des adultes. Suite à la ressemblance évocatrice de leurs noms, tous deux «bruyants » ${ }^{109}$, Mormô pourrait peut-être traduire plus exactement que les autres la figure horrifiante de Gorgô dans l'imagination enfantine ${ }^{110}$. Association sonore dont Hippolyte pourrait s'être fait l'écho; association aussi qui, de la part d'un prêtre chrétien, pourrait être un clin d'œil : il dit assez que la lécanomancie est une pratique de charlatans, païens de surcroît. Dès lors, associer l'épouvantail d'enfants à la déesse ainsi qu'à un épouvantail d'adultes, dans l'invocation même qui lui est adressée, exprimerait assez bien la pusillanimité de telles pratiques, ainsi que celle des gens qui s'y adonnent, et reviendrait à traiter tout cela comme " conte de vieille femme».

Pour en revenir au rapport entre Mormô et Gorgô, on pourrait également passer par l'association des deux personnages au cheval. Le «cheval qui mord » de Théocrite exprime la peur de la morsure, une crainte essentiellement enfantine ${ }^{111}$; notons que les chevaux anthropophages ne manquent pas dans les mythes grecs ${ }^{112}$. Mais le terme mormô est utilisé ici comme une exclamation, exprimant l'effroi que la mère veut communiquer à son enfant, tout en étant associé au cheval ${ }^{113}$. Or, ce dernier est également associé à Gorgô qui traduit dans la pensée grecque la nature inquiétante du cheval ${ }^{144}$. En effet, quand il est nerveux et impétueux le cheval peut être qualifié de

107 Cf. supra, n. 24 et 26

J.-P. Vernant, La mort dans les yeux. Figures de l'autre en Grèce ancienne, Paris, 1985, p. $61-62$.

109 Cf. supra, n. 14, 15 et 99; infra, n. 128.

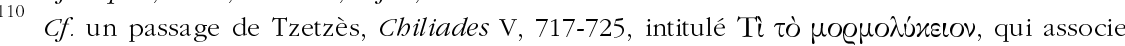
Mormô aux Gorgones.

111 La phobie des chevaux, et surtout de leur morsure, est courante chez l'enfant ( $c f$. S. Freud, "Analyse d'une phobie chez un petit garçon de 5 ans (Le petit Hans) », in Cinq Psychanalyses, trad. M. BONAPARTE, R.M. LeEwenstein, Paris, 1954, p. 93-198) et peut même se prolonger jusqu'à l'âge adulte ( $c f$. G. DEvereux, «Les chevaux anthropophages dans les mythes grecs », REG 88 [1975], p. 203-205). D'ailleurs, les Grecs muselaient leurs chevaux car ils craignaient leur morsure : Xénophon, De l'art équestre $\mathrm{V}, 3$.

112 Glaucos, fils de Sisyphe, prit part aux jeux funèbres en l'honneur de Pélias; vaincu à la course de quadriges, il se fit par la suite dévorer par ses juments : Iliade VI, 154; Eschyle, fr. 3642 (éd. RADT). Le cruel Diomède qui jetait les étrangers en pâture à ses juments, en subit le même sort : Diodore de Sicile, IV, 15, 3-4; Élien, Sur la nature des animaux XV, 25; Strabon, VII, F 43 et 46; Hygin, Fables, 30; 250. Hippomenès enferma sa fille, qui n'était plus vierge, avec un cheval, jusqu'à ce que l'animal, affamé, la dévore : Diodore de Sicile, VIII, 22. Anthos, fils d'Autonoos et d'Hippodamie, poussa les chevaux de son père hors de leur pâturage et fut dévoré par eux : Antoninus Liberalis, Métamorphoses VII, etc.

113 Et c'est ainsi que le scholiaste comprend le passage : cf. supra, n. 18.

114 M. Detienne, J.-P. Vernant, Les ruses de l'intelligence, la mètis des Grecs, Paris, 1974, p. 182 . 
gorgos : «terrible, inquiétant» ${ }^{115}$. Or «dans le mot gorgos, il y a l'image d'un regard de Gorgone », une Gorgô à tête de cheval ${ }^{116}$. Et il faut ajouter à la nature inquiétante de l'animal toutes les sonorités qui lui sont propres ${ }^{117}$. Le cheval est un animal vite effrayé selon les anciens. Il l'est par des «visions

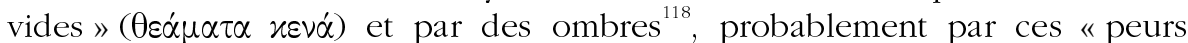
vides » que sont les $\mu o ́ g \mu{ }^{119}$. Il n'est donc pas étonnant que Mormô et Gorgô, deux "Puissances de Terreur» aux noms d'une sonorité évocatrice, soient toutes deux associées à un animal «terrible » comme le cheval.

De plus, le mormolukeion est à Mormô ce que le gorgoneion (ou le gorgeion) est à Gorgô ${ }^{120}$. D'ailleurs, Plutarque ${ }^{121}$ parle des masques qui effrayent les enfants en usant du terme moins connoté de prosôpeion. Pour que les petits enfants ne craignent plus les masques, il faut les retourner, les leur montrer sous toutes les coutures. Ce qui n'est pas sans rappeler une injonction d'Epictète de retourner le masque effrayant de la mort pour voir qu'il ne mord pas $^{122}$. Le texte de Plutarque prouve que le masque appelé mormolukeion n'a pas le monopole d'effrayer les enfants : tout masque peut être un épouvantail ${ }^{123}$. Pollux se contente à deux reprises ${ }^{124}$ de fournir une liste de termes désignant le masque en général: $\pi \varrho 0 \sigma \omega \pi \varepsilon i o v, \pi \varrho 0 \sigma \omega \pi i \varsigma$,

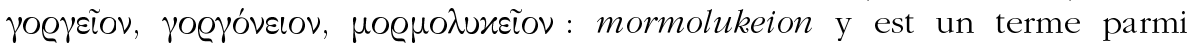
d'autres, tout comme le gorgeion/gorgoneion. Suivant une scholie à Aristophane ${ }^{125}$, le terme mormolukeion désignerait un masque difforme. Il n'est donc pas facile de déterminer à quel genre de masque on avait affaire.

115 Xénophon, De l'art équestre X, 17.

116 Gorgô à la tête chevaline, mère de Pégase (par Poséidon) : cf. Detienne, Vernant, o.c. (n. 114), p. 181 .

117 VERNANT, o.c. (n. 108), p. 53.

118 S. GEORGOUDI, Des chevaux et des boufs dans le monde grec (Réalités et représentations animalières à partir des livres XVI et XVII des Géoponiques), Paris/Athènes, 1990, n. 30, p. 137.

119 Cf. supra, n. 16

120 VERNANT, o.c. (n. 108), p. 61-62.

121 Plutarque, De l'exil, 5 (Mor., 600e).

122 Épictète, Entretiens II, 1, 13-7.

123 Pas uniquement pour les enfants d'ailleurs : selon I. LOUCAS, « Ritual Surprise and Terror in Ancient Greek Possession-Dromena », Kernos 2 (1989), p. 97-104, on utilisait des masques dans certains rituels pour créer une violente surprise et la peur chez le spectateur. Il souligne la fonction de imitatio dei du masque, qui pouvait transformer un être humain en être surnaturel (sur cette fonction du masque $c f$. Th. KARAGIORGA, 'Tête gorgonéenne'. Origine et signification de la forme gorgonéenne dans le culte et l'art de l'époque archaïque (en grec), Athènes, 1970, p. 112132; W. BuRKerT, Greek Religion, Archaic and Classical, trad. J. RAFFAN, Oxford, 1985 (1 éd. Stuttgart, 1977), p. 103. Th. Feldman, "Gorgo and the Origins of Fear », Arion 4 (1965), p. 484494, essaye de trouver la source de la peur que peut provoquer le gorgoneion, en l'occurrence un visage sans corps, un masque; elle souligne que la peur du démembrement, et particulièrement de la tête coupée, serait la peur la plus profonde et la plus fondamentale déjà chez les primates; selon l'auteur, Gorgô évoquait les peurs les plus primitives de l'homme, tandis que Mormô connotait spécifiquement les peurs des enfants.

124 Pollux, Onomasticon IV, 115 et X, 167.

125 Cf. supra, n. 49. Scholia in Aristophanis Pacem, 474 
Françoise Frontisi-Ducroux ${ }^{126}$ considère qu'il faut prêter «au mormolukeion une bouche dentue, dévorante, aussi menaçante que celle de la Gorgone », car Mormô est à l'évidence associée à la morsure, « expression privilégiée des terreurs enfantines ». En revanche, lorsque ce mot s'applique aux masques signalant les sanctuaires de Dionysos, il ne peut évidemment s'agir des masques du dieu lui-même. "Souriant ou sévère, Dionysos n'a rien d'un épouvantail ». F. Frontisi-Ducroux pense qu'il s'agit plutôt de masques de satyres ou de silènes, attestés par l'archéologie, qui seraient ainsi désignés comme des mormolukeia. Il s'agirait donc, comme les gorgoneia, de masques à vocation apotropaïque et prophylactique : «de petits masques de métal ou de terre cuite, perforés de trous de suspension, dont les traits sont conformes à deux modèles canoniques : avec les Gorgones, les satyres grimaçants fournissent l'essentiel de ces figurations ${ }^{127}$.

Ainsi les relations entre Mormô/Mormolukê et Gorgô/Gorgura se confirment-elles : il semble naturel que les masques d'acteurs dérivant du nom de l'une ou de l'autre soient interchangeables dans leur fonction d'épouvantails d'enfants ${ }^{128}$.

\section{Mormô, l'épouvantail et le masque}

De toute manière, le fait que le mormolukeion désigne le «masque » en général montre que ce terme possède la nature même du masque. Tout masque dissimule la véritable nature de celui qui le porte. Cette dimension de secret est effrayante en elle-même et rappelle la capacité de métamorphose de Mormô. On ne sait pas sous quel aspect, sous quel visage et, par là, sous quel masque elle essaiera de nous atteindre. Elle se dissimule derrière son aspect ponctuel, comme le mormolukeion dissimule le visage de l'acteur (ou le vide). Or, disent certaines sources, il faut retourner le mormolukeion (ou le prosôpeion) pour voir qu'il ne cache qu'un vide inoffensif. Inoffensif et quelque peu ridicule : « le risible, dit Aristote ${ }^{129}$, est une partie du laid ${ }^{130}$ (...) ainsi, par exemple, le masque comique est laid et difforme ».

126 Frontisi-DuCROuX, o.c. (n. 52), p. 13-14.

27 Ibid., p. 14. Cependant, les masques suspendus pouvaient être de diverses sortes, provenant d'offrandes au sanctuaire, par exemple le masque consacré après un concours théâtral lors de jeux en l'honneur de Dionysos, ou par quelqu'un qui a fini sa carrière théâtrale etc. et mormolukeion est un terme assez général que pour désigner toutes sortes de masques. Cf. Ch.G. SIMON, The Archaic Votive Offerings and Cults of Ionia, thèse de doctorat, Université de Californie, Berkeley, 1986, p. 376-378.

${ }^{128}$ Notons une fois de plus les associations sonores de tous ces termes: MORM, GORG et MORMOR (Mormô, Gorgô, mormoros, mormoi etc.) sont des sonorités effrayantes, GORGUR (Gorgura) évoque des gargouillements, et MORMUR (mormuraia) des bruits sourds, des grondements, des murmures : cf. SKODA, o.c. (n. 15), $\mathbb{\$} 3.103$, p. 106. Pour les termes mormoros, mormoi et mormuraia, cf. supra, n. 16.

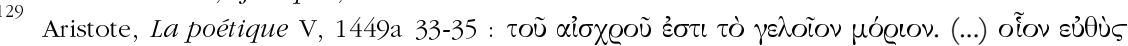

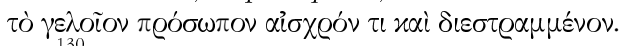

Cf. A. JAUlin, "Le rire logique: usages de geloion chez Aristote», in Desclos, o.c. (n. 104), p. 319-331. 
Comme derrière un masque, Mormô se dissimule derrière ses nombreux aspects. Le mormolukeion, tout en dissimulant la véritable identité de ce qui se trouve derrière (peut-être le vide), n'en devient pas moins l'instrument de révélation de Mormô, n'en rend pas moins sa présence effective : celle de l'épouvante. Le mormolukeion manifeste la présence de Mormô de façon subtile : elle peut ou non être là mais, dans les deux cas, elle est terrifiante. Il est par ailleurs significatif que ce même mormolukeion désigne par sa présence le Dionysion, le temple du dieu au masque. La figure de Mormô combinant en elle l'humain, le bestial et le surnaturel, renvoie au dieu à travers les masques; précisément à celui qui, selon Jean-Pierre Vernant ${ }^{131}$, «brouille les frontières entre le divin et l'humain, l'humain et le bestial, l'ici et l'au-delà ». Le dieu dont la vision «consiste à faire éclater du dedans, à réduire en miettes cette "vision" positive qui se prétend la seule valable et où chaque être a sa forme précise, sa place définie, son essence particulière dans un monde fixe assurant à chacun sa propre identité à l'intérieur de laquelle il demeure enfermé toujours semblable à lui-même » ${ }^{132}$. Dans un autre registre, Mormô brouille aussi les limites, elle représente un chaos où dieux, hommes et bêtes ne seraient pas différenciés : elle n'a pas de forme fixe, elle participe des trois états. Son acte (dévorer ses propres enfants) l'a séparée du monde humain et du statut qui était jusqu'alors le sien : en commettant ce crime atroce, elle est rentrée dans un monde d'où l'on ne revient plus; elle est devenue autre, tout en gardant un pied dans le monde des humains, toujours susceptible d'être là et d'entrer dans les chambres enfantines.

«Dépassement de toutes les formes, jeu avec les apparences, confusion de l'illusoire et du réel » : ainsi parle Jean-Pierre Vernant ${ }^{133}$ à propos du dieu au masque. Expression qui pourrait également évoquer Mormô : la confusion de l'illusoire et du réel se retrouve dans son aspect même de masque, le jeu avec les apparences dans son pouvoir même de métamorphose. Loup, cheval, masque, nourrice, elle fait partie des radotages de vieilles femmes, seules capables de croire à leurs contes, partageant la crédulité des enfants auxquels elles s'adressent, mêlant dans leurs récits le vrai et le faux, l'illusoire et le réel, introduisant l'invisible terrifiant dans les chambres enfantines pour charmer les oreilles et adoucir les comportements. En effrayant, mais aussi en tenant en haleine leurs auditeurs par des récits où - il est vrai - il y a des personnages terrifiants, mais s'ils ne l'étaient pas on s'ennuierait (et redeviendrait turbulent). Il faut que ces personnages soient fascinants pour focaliser l'intérêt de l'auditoire. Il n'est pas vrai que Mormô existe mais elle est peut-être ici : on y croit sans y croire, comme dirait Paul Veyne ${ }^{134}$, et le fait que tant de sources y fassent allusion, tant d'auteurs différents, nous amène comme à une expression fixe : elle n'existe pas mais on en a peur (du moins en ce qui concerne les enfants et les lâches). Comme le mormolukeion, Mormô n'est qu'appa-

\footnotetext{
131 J.-P. VERNANT, Figures, idoles, masques, Paris, 1990, p. 225

132 Ibid., p. 229.

133 Ibid., p. 235 : plus précisément dans la tradition des Bacchantes d'Euripide.

134 VEYNE, o.c. (n. 69), p. 94
} 
rence vide, décor creux : c'est particulièrement manifeste dans le récit de Philostrate $^{135}$. Tout ce qui entoure la créature qui a pris l'apparence d'une belle femme pour dévorer le jeune Ménippe, créature elle-même désignée comme phasma, «apparition »" sa vaisselle, sa maison, ses serviteurs, tout disparaît d'une manière ou d'une autre (ou bien littéralement, ou bien en abandonnant la maison); tout n'est qu'apparence, dit Apollonios, y compris la mariée. Et derrière elle se cache un être épouvantable, mais qui finalement disparaît lui aussi.

\section{Mormô, un être verbal}

Mormô semble se rapprocher, selon la définition de Nicole Belmont ${ }^{137}$, de la catégorie des " êtres verbaux » (après celles des créatures anthropomorphes et zoomorphes), ces êtres fantastiques dont la seule caractéristique semble être le nom, sur lequel repose toute la vertu d'effroi qu'ils suscitent. Il leur manque la description physique, la légende, les faits et les gestes.

À ce propos, on pourrait comparer les verbes dérivés de mormô, mormussomai, mormoluttomai, avec l'expression française médiévale de «faire barbo ${ }^{138}$, qui servait à effrayer les enfants. Selon Jacques Berlioz, un croquemitaine féminin nommé Babou (mentionné pour la première fois au XVI siècle) proviendrait d'un tel être verbal, nommé barbo ou barbou, dès le XIII siècle. On «faisait barbo » aux enfants pour les faire reculer; il est en outre associé au loup ou au loup-garou" "Tout se passe comme si dans l'invocation l'être fantastique primait l'animal sauvage, comme si le croquemitaine prenait le pas sur le danger réel ${ }^{140}$. Or n'est-ce pas le cas dans le nom même de Mormô, qui reste le nom d'un croque-mitaine tout en gardant sa relation avec le loup par les attestations de Mormolukê ou du mormolukeion? Le barbo est également en relation avec larua, un terme latin qui « désigne tout à la fois un fantôme malfaisant et un masque » ${ }^{141}$. Les laruae ${ }^{142}$ seraient

135 Philostrate, Vie d'Apollonios de Tyane IV, 25.

136 Cf. R. PIETTRE, Le corps des dieux dans les épiphanies divines en Grèce ancienne, thèse de

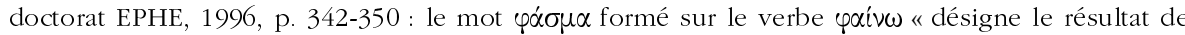
l'action verbale 'apparaître' : il représente soit l'objet en tant qu'il apparaît (fantôme, présage), soit le fait même de l'apparition (vision). Cet objet ou cette vision ne sont cependant ainsi désignés que s'ils sont considérés et vécus comme frappants et surnaturels, ce qui veut dire que leur cause demeure obscure, ou qu'elle s'efface entièrement derrière le seul 'apparaître' » (p. 345). Un phasma frappe les sens, il «réalise pleinement la violence impérieuse du paraître, toutes les

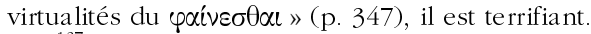

137 N. Belmont, «Comment on fait peur aux enfants », Topique 13 (1974), p. 101-125, surtout p. $112-115$

138 J. BerLIOZ, "Masques et croquemitaines. À propos de l'expression 'Faire barbo' au Moyen Âge ", Le monde alpin et rhodanien 10 (1982), p. 221-234.

139 Ibid., p. 225, citation de Doon de Mayence (chanson de geste du XIII ${ }^{e}$ s.), v. 1442-1443: "Je sais bien que le loup-garou (barbeus) ou le loup m'étranglera/ Si Dieu ne me vient en aide. »

140 Ibid

141 Ibid., p. 226 : en s'appuyant sur une note marginale «De larva vel Barbo » dans le Traité de prédication d'Étienne de Bourbon, datant également du XIII ${ }^{\mathrm{s}} \mathrm{s}$. 
les âmes des individus ayant commis quelque crime ou bien décédés de mort violente et qui reviennent parmi les vivants pour les tourmenter. Dans la tradition chrétienne, ils prirent le sens de «fantômes diaboliques épouvantant les bambins ». Déjà chez les Romains la nature des larves est de «terrifier les petits enfants et de murmurer dans les coins sombres ${ }^{143}$. Ce qui n'est évidemment pas sans rappeler les murmures ou grondements associés à Mormô ${ }^{144}$. De plus, larua signifie aussi «masque». Or «faire le barbo» signifierait également "faire le masque » ${ }^{145}$, effrayer les enfants au moyen d'un masque. Finalement le «faire barbo» du Moyen Âge français est fort comparable au «faire mormô» (mormoluttomai, mormussomai) ${ }^{146}$ des Grecs. Le croquemitaine français Babou est lié au loup, au masque et à l'interjection effrayante barbo, ce qui en fait un bon point de comparaison avec Mormô.

L'intérêt de cette comparaison entre deux êtres verbaux aussi éloignés culturellement, est que pour tous deux, comme le dit Nicole Belmont ${ }^{147}$, leur attribut essentiel est le nom par lequel on les désigne : «leur description et leur histoire sont secondaires au regard de leur nom». L'autre point intéressant est que finalement ce "procédé d'éducation participant d'une véritable pédagogie de la peur et visant à délimiter l'espace de l'enfant par l'emploi d'un croque-mitaine ${ }^{148}$, d'un être verbal auquel on peut attribuer toute forme d'action et tout aspect, se retrouve de manière comparable dans les récits de chambres enfantines fort éloignées mais somme toute pas si différentes.

Ce qui est frappant après l'examen des attestations de termes tels que Mormô, Mormolukê et mormolukeion, c'est qu'ils sont utilisés de manière très courante. Les auteurs anciens semblent bien avoir été épouvantés par eux

142 Cf. Apulée, Du dieu de Socrate, 153, et le commentaire de J. BEAujEu (éd.) p. 232-233.

143 Saint Jérôme, Hebraicae quaestiones in libro Geneseos, éd. P. de LAGARDE, t. I, 1, Corpus Christianorum, Series Latina, 72, Turnhout, 1959, Préface, p. 2, 14-17. Sur les larves chez les Romains, $c f$. É. JobBE-Duval, Les morts malfaisants (Larvae, Lemures) d'après le droit et les croyances populaires des Romains, Chambéry, 2000² (1924), passim, surtout p. 44-50.

144 Cf. SKODA, o.c. (n. 15), \ 3.87, p. 98.

145 BERLIOZ, l.c. (n. 138), p. 228. Et même faire peur aux enfants avec des masques à barbe : p. 230 .

146 Voir par exemple l'emploi intéressant du verbe par Callimaque, Hymne à Artémis, (III) 65-71, où ce sont les filles des dieux qui sont effrayées par des épouvantails, lorsqu'elles sont désobéissantes; la mère fait appel aux Cyclopes, et Hermès se déguise en mormolukeion pour effrayer $(\mu \circ Q \mu u ́ \sigma \sigma \varepsilon \tau \alpha l)$ une fillette en se barbouillant de cendre noire et en surgissant d'une chambre reculée : "visage insolite, face noyée de nuit, sans plus de traits reconnaissables » (J.P. VERnANT, "L'autre de l'homme : la face de Gorgô », in M. Olender (éd.), Mélanges Poliakov. Le racisme, mythes et sciences, Bruxelles/Paris, 1981, p. 141-156, p. 150) que n'en a une Mormô multiforme, sans aspect bien défini; scène familière, où le dieu joue avec la petite fille, comme le garçon qui poursuit un autre enfant avec un masque de satyre (cf. supra, n. 52). Sur le « masque de suie» utilisé par Hermès, $c f$. P. Ellinger, La légende nationale phocidienne. Artémis, les situations extrêmes et les récits de guerre d'anéantissement, BCH Suppl. 27 (1993), p. 175. Notons

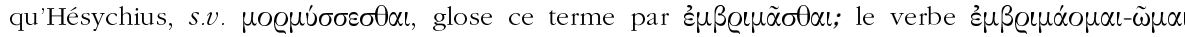
signifie « gronder, s'irriter contre quelqu'un ». Pourrait-on imaginer qu'Hermès ajoute la gronderie à la crainte qu'il inspire à la fillette pour la faire obéir ?

147 BELMONT, l.c. (n. 137), p. 125.

148 BerLioz, l.c. (n. 138), p. 232-233. 
dans leur enfance, et paraissent s'en souvenir précisément même si c'est pour s'en moquer. Mormô semble avoir fait partie intégrante de la prime éducation des Grecs, et les avoir ainsi rendu «sages » et « raisonnables ». Pourtant, elle n'a pas de figure bien définie et son histoire est très peu précise, comme si ce «flou artistique » qui caractérise cette créature faisait partie intégrante de sa personnalité. En effet, une créature sans forme ni histoire bien déterminées ouvre la porte à toutes les inspirations, à toutes les fantaisies. Il y a des noms effroyables (et de plus, dans le cas de Mormô, la sonorité même y contribue), et les nourrices peuvent leur prêter toute forme et tout méfait qu'elles veulent imaginer. Et cela vaut aussi pour les enfants : le «monstre » peut rester dans le noir, on ne le voit pas, on ne sait à quoi il ressemble, mais on n'en panique pas moins.

Maria PATERA

École Pratique des Hautes Études

Courriel : maria.patera@libertysurf:fr 